\title{
CARACTERIZAÇÃO PALINOFACIOLÓGICA DE UMA SUCESSÃO SEDIMENTAR OLIGOCÊNICA DA FORMAÇÃO TREMEMBÉ, BACIA DE TAUBATÉ
}

\author{
RENATA BRENAND ALVARENGA DAS CHAGAS, JOÃO GRACIANO MENDONÇA FILHO, \\ JOALICE DE OLIVEIRA MENDONÇA \\ LAFO/DEGL/IGEO/CCMN/UFRJ, Ilha do Fundão, 21949-900, Rio de Janeiro, RJ, Brasil. renata.brenand@ geologia.ufrj.br, \\ graciano@geologia.ufrj.br, joalice@geologia.ufrj.br

\section{TAÍSSA RÊGO MENEZES} \\ GEO/CENPES/PETROBRÁS, Ilha do Fundão, 21949-900, Rio de Janeiro, RJ, Brasil. taissamenezes@ petrobras.com.br
}

\begin{abstract}
ORGANIC FACIES CHARACTERIZATION OF A SEDIMENTARY SUCCESSION OF THE OLIGOCENE TREMEMBÉ FORMATION, TAUBATÉ BASIN. The main objective of this article was the organic facies characterization of an Oligocene sedimentary sequence, belonging to the Tremembé Formation (Taubaté Basin, east of São Paulo State, Brazil). To achieve that, 30 samples of sedimentary section with a depth of approximately $600 \mathrm{~m}$ were used, aiming to characterize the association of kerogen components using microscope techniques (transmitted white light and incident blue/ultralight light), and organic geochemistry (total organic carbon - TOC). In the sedimentary section studied, there was a predominance of particulate organic components from the palynomorph group, in relation to the total organic material, followed by components from the amorphous organic matter (AOM) and from the phytoclasts group. The palynomorph group is dominated by fresh water lacustrine algae from the Pediastrum and Botryococcus genera. The results of the geochemical analysis indicate grades of TOC and total sulfur (TS), with values up to $44.0 \%$ and $1.4 \%$, respectively. The integration of these results together with the organic facies parameters indicates that the analyzed sedimentary section represents a variation from a freshwater lacustrine environment with oxidant regime to a restricted saline lacustrine environment with a disoxic-anoxic regime.
\end{abstract}

Key words: organic facies, Tremembé Formation, Taubaté Basin, Oligocene.

RESUMO - O objetivo deste trabalho é a caracterização organofaciológica de uma sequência sedimentar oligocena pertencente à Formação Tremembé (bacia de Taubaté, leste do Estado de São Paulo). Para tanto, foram utilizadas 30 amostras de uma sucessão sedimentar de aproximadamente $600 \mathrm{~m}$ visando caracterizar a associação de componentes do querogênio a partir de técnicas de microscopia (luz branca transmitida e luz azul/ultravioleta incidente) e de geoquímica orgânica (carbono orgânico total-COT). Na sucessão sedimentar estudada, observou-se o predomínio de componentes orgânicos particulados do Grupo Palinomorfo em relação à matéria orgânica total, seguido por componentes da Matéria Orgânica Amorfa (MOA) e do Grupo Fitoclasto. O Grupo Palinomorfo é dominado por algas lacustres de água doce dos gêneros Pediastrum e Botryococcus. Os resultados das análises geoquímicas indicaram teores de COT e Enxofre (ST) apresentando valores de até $44,0 \%$ e 1,4\%, respectivamente. A partir da integração dos resultados obtidos, a sucessão sedimentar analisada apresentou uma variação desde um ambiente lacustre de água doce com regime oxidante até um ambiente lacustre salino restrito com regime disóxico-anóxico.

Palavras-chave: fácies orgânica, Formação Tremembé, bacia de Taubaté, Oligoceno.

\section{INTRODUÇÃO}

A caracterização organofaciológica da matéria orgânica utiliza a integração dos resultados de técnicas microscópicas (palinofácies) e de geoquímica orgânica (por exemplo, carbono orgânico total - COT). O conceito de palinofácies foi introduzido por Combaz (1964) como sendo "o estudo palinológico da associação total de matéria orgânica contida em um sedimento após a remoção da matriz sedimentar (mi- neral) pela acidificação com $\mathrm{HCl}$ (ácido clorídrico) e HF (ácido fluorídrico)".

A análise de palinofácies é o estudo palinológico de ambientes deposicionais e do potencial de rochas geradoras de hidrocarbonetos baseado na associação total de componentes da matéria orgânica particulada. Esta análise compreende o exame qualitativo e quantitativo do querogênio, integrando todos os aspectos dos componentes da matéria orgânica, como a identificação dos componentes particulados indivi- 
duais, determinação de suas proporções relativas e seu estado de preservação (Tyson, 1995).

Neste trabalho foram realizadas análises de palinofácies associadas a técnicas de geoquímica orgânica (fácies orgânica), com o objetivo principal de estudar a faciologia orgânica das rochas de um testemunho de idade oligocênica da bacia de Taubaté, Formação Tremembé, caracterizando o paleoambiente neste sistema deposicional.

\section{CONTEXTO GEOLÓGICO}

A bacia de Taubaté está localizada a nordeste do Estado de São Paulo (Figura 1) e apresenta $170 \mathrm{~km}$ de comprimento na direção NNW-SSE e, aproximadamente, 20 km de largura, distribuída em uma espessura sedimentar média de $800 \mathrm{~m}$ (Fernandes, 1993). A bacia é parte de um conjunto de bacias tafrogênicas pertencentes ao "Rift Continental do Sudeste do Brasil" (RCSB), cuja origem está relacionada à tectônica distensiva de idade terciária. A sedimentação é tipicamente continental, com depósitos sedimentares de granulometria grossa nas bordas falhadas da bacia, além de depósitos arenosos e argilosos na sua parte central, ligados a ambientes de sedimentação flúvio-lacustres (Riccomini, 1989).

A Formação Tremembé pertence ao Grupo Taubaté, de idade oligocênica (Figura 2). É formada predominantemente por uma sucessão sedimentar de rochas essencialmente microclásticas (siltitos, argilitos e folhelhos) ricas em matéria orgânica e representa um sistema lacustre fechado, oligomítico e eutrófico desenvolvido em clima semiárido (Torres-Ribeiro, 2004). Fernandes (1993) e Molinari (2003) descreveram a Formação Tremembé como sendo composta por argilitos maciços, folhelhos papiráceos, ritmitos (intercalação de marga/calcário e folhelho), arenitos e calcários. Seus depósitos possuem geometria tabular irregular, com espessura máxima conhecida de cerca de 400 m. Geograficamente, a Formação Tremembé ocorre apenas nas sub-bacias de Roseira, Quiririm e São José dos Campos.

De acordo com Riccomini (1989), a bacia de Taubaté corresponde a um sistema lacustre do tipo playa-lake, de idade oligocênica, desenvolvido na porção central da bacia de Taubaté e, de forma mais restrita, na bacia de São Paulo. Já Torres-Ribeiro (2004), ao contrário dos modelos propostos por outros autores, entende que a Formação Tremembé não pode ser classificada como um sistema deposicional do tipo playa-lake, pois não foram encontrados registros associados a depósitos evaporíticos, mesmo com a presença de camadas de calcário, que estão associadas a ambiente de clima mais seco.

\section{MATERIAL E MÉTODOS}

Para este trabalho, foi realizado o estudo da faciologia orgânica (palinofácies e geoquímica orgânica) em amostras da Formação Tremembé. Para tanto, foram utilizadas amostras de um testemunho de sondagem Pinda 1-SP que se encontra localizado a noroeste da bacia de Taubaté e a nordeste da cidade de Pindamonhangaba (SP). O intervalo analisado apresenta uma espessura com aproximadamente $600 \mathrm{~m}$. Um total de trinta amostras da Formação Tremembé foram coletadas, de 20 em $20 \mathrm{~m}$, atingindo profundidade de até $515 \mathrm{~m}$.

\section{Preparação de lâminas organopalinológicas}

A preparação do material para análise de palinofácies foi realizada utilizando-se os procedimentos palinológicos padrões não oxidativos descritos por Tyson (1995), Mendonça Filho (1999) e Mendonça Filho et al. (2009). As amostras foram fragmentadas e, aproximadamente, $20 \mathrm{a} 40 \mathrm{~g}$ de material foi separado para obtenção de um concentrado de querogênio. A primeira etapa do processamento químico consistiu na acidificação da amostra com o ácido clorídrico (37\%) para eliminação da fração carbonática. Na segunda etapa do processamento utilizou-se ácido fluorídrico (40\%) para eliminação da fração silicosa. A amostra foi novamente acidificada com $\mathrm{HCl}(10 \%)$, para eliminação dos possíveis fluorsilicatos formados durante as etapas anteriores. Utilizou-se o cloreto de zinco $\left(\mathrm{ZnCl}_{2}\right)$ para separação por flotação da fração orgânica. Após esse processamento, foram confeccionadas lâminas organopalinológicas com o resíduo orgânico.

\section{Análise de palinofácies}

A análise de palinofácies envolveu o exame quantitativo (contagem de 300 a 500 partículas) e qualitativo (identificação das partículas) dos grupos e subgrupos de componentes do querogênio, por meio de técnicas de microscopia sob luz branca transmitida e luz azul/ultravioleta incidente (fluorescência). Tal contagem obedeceu à classificação dos grupos e subgrupos da matéria orgânica proposta por Tyson (1995), Mendonça Filho (1999) e Mendonça Filho et al. (2002, 2009). Após a contagem dos componentes orgânicos particulados, os valores absolutos foram recalculados para valores percentuais

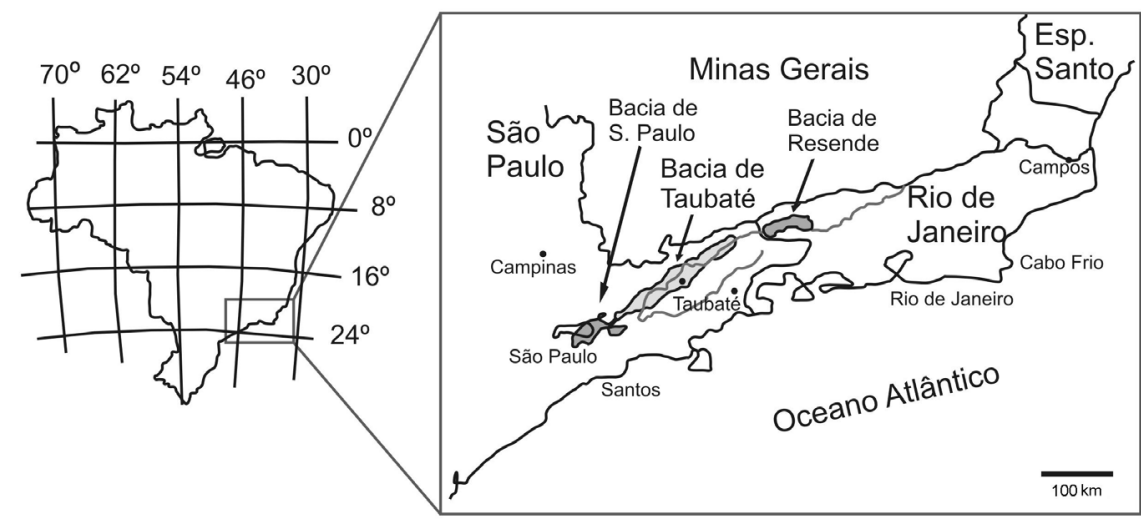

Figura 1. Mapa de localização da bacia de Taubaté (modificado de Fernandes, 1993).

Figure 1. Location map of Taubaté Basin (modified from Fernandes, 1993). 
e normalizados a $100 \%$ e diagramas binários foram confeccionados, para uma melhor visualização dos resultados.

\section{Análises geoquímicas}

A análise de carbono orgânico total (COT) foi obtida utilizando-se o forno de indução do determinador de carbono WR12 LECO. O analisador SC-144DR LECO é um instrumento de quantificação simultânea de carbono e de enxofre, a partir de um detector de infravermelho. Os resultados de COT expressam a quantidade de matéria orgânica presente nos sedimentos.

\section{Tratamento estatístico}

A partir da análise quantitativa dos componentes orgânicos particulados foi realizado o tratamento estatístico dos dados. Esses dados foram recalculados para valores percentuais e submetidos à análise de agrupamento (análise cluster), entre os grupos e subgrupos do querogênio (coeficiente de correlação 1-Pearson-r / Modo R) e para a observa- ção de similaridades entre as amostras (Modo Q), utilizando o programa Statistic Basic versão 6.0 (Valentin, 2000).

\section{RESULTADOS}

\section{Palinofácies}

A partir da análise organocomposicional ao longo do testemunho, observaram-se os três principais grupos da matéria orgânica (Fitoclasto, Matéria Orgânica Amorfa - MOA e Palinomorfo), com predominância do Grupo Palinomorfo, representado pelas algas Chlorococcales do gênero Botryococcus. Essas colônias apresentam-se bem formadas, com uma coloração que varia de castanho claro a escuro sob luz branca transmitida e coloração amarela intensa sob fluorescência (Tabela 1; Figuras 3A-B). Algumas amostras apresentam essas algas em estado amorfizado, com coloração castanha escuro sob luz branca transmitida e laranja sob fluorescência.

Tabela 1. Valores percentuais dos principais grupos e subgrupos do querogênio. $\left(^{*}\right)$ Valor percentual dos três principais grupos da matéria orgânica em relação a matéria orgânica total. $\left(^{* *}\right)$ Valor percentual dos sugbrupos dos palinomorfos em relação ao Grupo Palinomorfo total. Abreviaturas: Fito, fitoclasto; MOA, matéria orgânica amorfa; Palino, palinomorfo; Espor., esporomorfos; Botry., Botryococcus; Pedi., Pediastrum.

Table 1. Values in percentage of the main groups and subgroups of Kerogen. $\left(^{*}\right)$ Values in percentage of the three groups of organic matter toward total organic matter. ${\left({ }^{*}\right)}^{*}$ Values in percentage of the palynomorphs subgroups toward Palynomorph Total Group. Abbreviations: Fito, phytoclast; MOA, amorf organic matter; Palino, palynomorph; Espor., sporemorph; Botry., Botryococcus; Pedi., Pediastrum.

\begin{tabular}{|c|c|c|c|c|c|c|c|}
\hline \multirow{2}{*}{ Amostra } & \multirow{2}{*}{ Prof. (m) } & \multirow{2}{*}{ Fito* } & \multirow{2}{*}{ MOA* } & \multirow{2}{*}{ Pa lino* } & \multicolumn{3}{|c|}{ Palino morfos } \\
\hline & & & & & Espor.** & Botry.** & Pedi.** \\
\hline P37 & 23,50 & 7,9 & 6,0 & 86,1 & 51,1 & 7,3 & 27,7 \\
\hline $\mathrm{P} 73$ & 40,80 & 0,0 & 2,0 & 98,0 & 1,2 & 7,9 & 88,9 \\
\hline P115 & 59,20 & 23,5 & 38,7 & 37,8 & 11,6 & 25,0 & 1,2 \\
\hline P 140 & 78,50 & 3,3 & 3,9 & 92,8 & 3,6 & 4,7 & 84,5 \\
\hline P164 & 97,30 & 49,2 & 40,5 & 10,3 & 5,2 & 4,6 & 0,5 \\
\hline $\mathrm{P} 187$ & 115,65 & 4,7 & 28,1 & 67,3 & 12,0 & 42,1 & 13,2 \\
\hline P208 & 134,80 & 11,1 & 27,3 & 61,6 & 13,6 & 43,2 & 4,8 \\
\hline P227 & 154,00 & 15,5 & 24,7 & 59,8 & 10,2 & 9,2 & 40,4 \\
\hline P243 & 171,28 & 3,7 & 0,0 & 96,3 & 8,7 & 3,4 & 84,2 \\
\hline P254 A & 188,80 & 31,8 & 58,1 & 10,1 & 4,1 & 5,5 & 0,5 \\
\hline P266 & 205,98 & 5,7 & 79,4 & 14,9 & 3,6 & 8,7 & 2,7 \\
\hline P273 & 220,00 & 5,6 & 0,0 & 94,4 & 4,4 & 86,8 & 3,2 \\
\hline P288 & 241,90 & 14,0 & 47,2 & 38,8 & 6,7 & 5,9 & 26,1 \\
\hline P305 & 260,10 & 7,1 & 75,1 & 17,8 & 4,0 & 12,0 & 1,8 \\
\hline P326 & 280,60 & 5,7 & 89,9 & 4,5 & 0,3 & 4,2 & 0,0 \\
\hline P344 & 298,40 & 1,3 & 40,8 & 58,0 & 2,9 & 1,9 & 53,2 \\
\hline P364 & 318,65 & 28,6 & 1,8 & 69,6 & 44,5 & 8,0 & 17,1 \\
\hline P381 & 335,65 & 3,3 & 66,2 & 30,5 & 7,7 & 9,3 & 13,5 \\
\hline P416 & 371,10 & 13,9 & 0,0 & 86,1 & 2,4 & 49,6 & 34,0 \\
\hline P432 & 388,40 & 16,8 & 0,0 & 83,2 & 23,9 & 44,7 & 14,7 \\
\hline P443 & 406,90 & 4,0 & 8,5 & 87,5 & 0,0 & 87,2 & 0,3 \\
\hline $\mathrm{P} 450$ & 418,00 & 93,1 & 0,0 & 6,9 & 6,9 & 0,0 & 0,0 \\
\hline $\mathrm{P} 453$ & 421,65 & 92,0 & 0,0 & 8,0 & 8,0 & 0,0 & 0,0 \\
\hline P459 & 438,05 & 51,6 & 1,0 & 47,4 & 9,2 & 19,1 & 19,1 \\
\hline P476 & 455,5 & 81,7 & 0,0 & 18,3 & 14,0 & 2,4 & 1,8 \\
\hline P492 & 472,15 & 92,5 & 0,0 & 7,5 & 1,2 & 6,3 & 0,0 \\
\hline P512 & 490,55 & 56,0 & 13,8 & 30,2 & 0,3 & 28,1 & 1,8 \\
\hline
\end{tabular}


Elementos do gênero Pediastrum incluem outro subgrupo de maior ocorrência no Grupo Palinomorfo, que sob luz branca transmitida apresentam-se translúcidos e sob fluorescência têm colorações variando de amarelo a amarelo-esverdeado (Tabela 1; Figuras 3C-D). Essas algas, em algumas amostras, encontram-se amorfizadas, translúcidas sob luz branca transmitida e com coloração esverdeada sob fluorescência, com aspecto "menos denso" (mais fina) (Figuras 4M-N). Os demais subgrupos do Grupo Palinomorfo apresentam baixa ocorrência, representados pelos esporomorfos (esporos e grãos de pólen). Foi registrada também a presença de Azolla, uma mássula de esporos de pteridófitas aquáticas (Tabela 1; Figuras 3E-P, 4C-D).

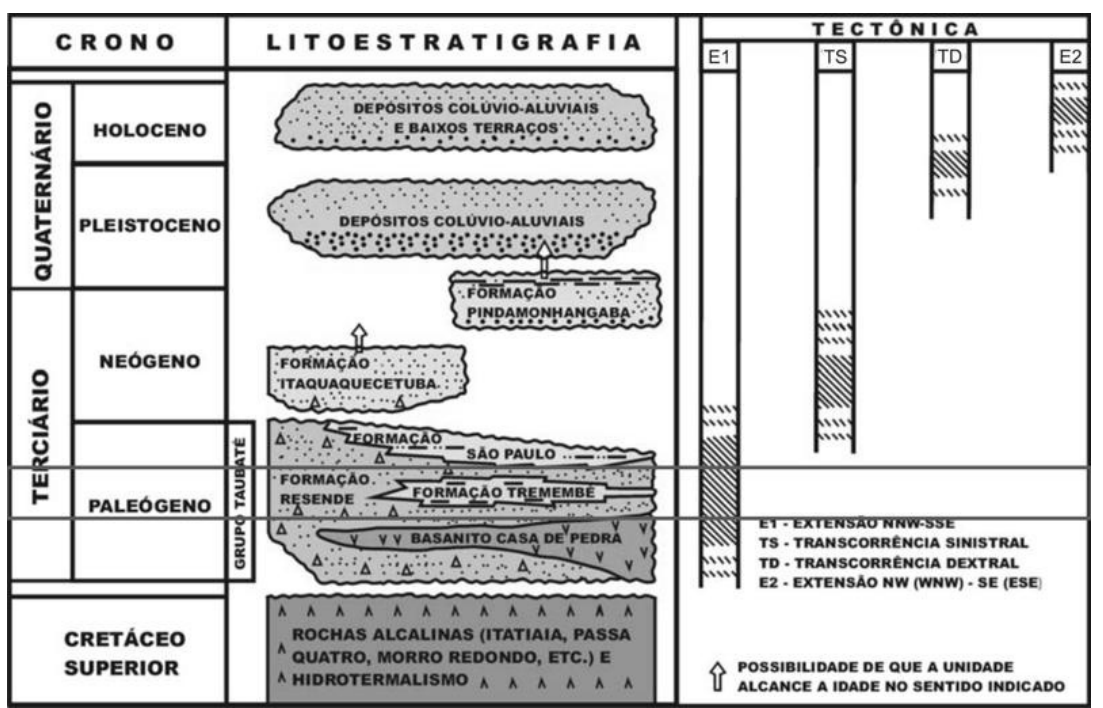

Figura 2. Quadro litoestratigráfico do segmento central do RCSB, destacando o Grupo Taubaté e a Formação Tremembé (segundo Torres-Ribeiro, 2004).

Figure 2. Litostratigraphic diagram of central segment of RCBS, bouncing the Taubaté Group and the Tremembé Formation (after Torres-Ribeiro, 2004).
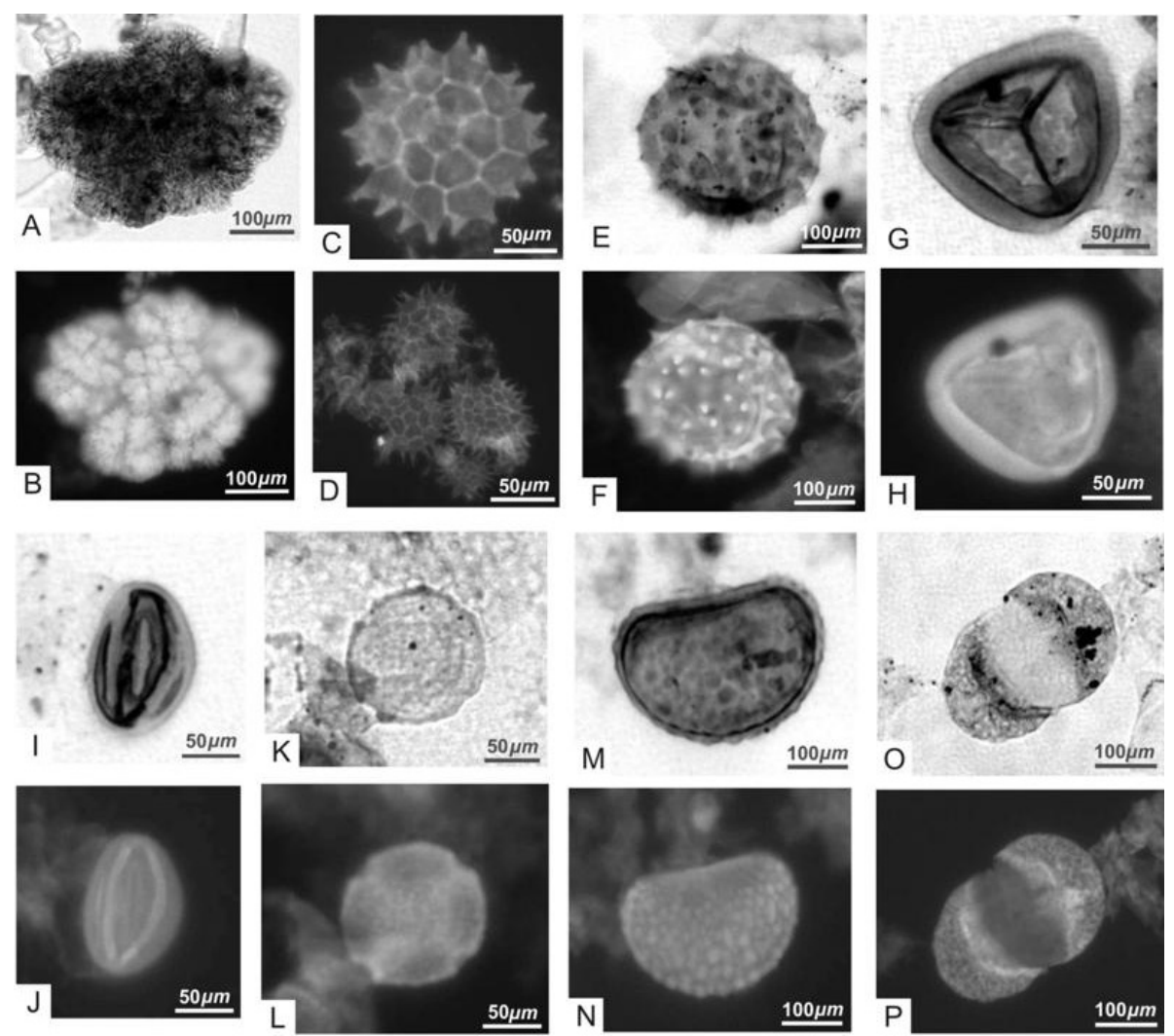

Figura 3. A-B, Botryococcus; C-D, Pediastrum; E-F, esporo com ornamentação; G-H, esporo; I-J, Rhoipites; K-L, Ulmodeipites krempii; M-N, Verrucatosporites; O-P, Podocarpidites marwickii. Fotomicrografias em A, E, G, I, K, M, O sob luz branca transmitida; em C, D, F, H, J, L, N, P sob luz azul/UV incidente (fluorescência).

Figure 3. A-B, Botryococcus; C-D, Pediastrum; E-F, spore with ornamentation; G-H, spore; I-J, Rhoipites; K-L, Ulmodeipites krempii; MN, Verrucatosporites; O-P, Podocarpidites marwickii. Photomicrographs in A, E, G, I, K, M, O under transmitted white light; in C, D, F, H, J, L, N,P under incident blue light/ultralight light (fluorescence). 
O Grupo MOA, oriundo de ataque microbiológico e provavelmente derivado de bactérias, fitoplâncton e agregados orgânicos degradados, pode formar grumos ou ser finamente dispersos. Sob luz branca transmitida, apresenta-se em grumos com coloração variando de marrom a amarelo escuro e sob fluorescência, na maioria das vezes, encontra-se mais fina com coloração amarelo esverdeado. Às vezes, a partícula encontra-se com aspecto mais denso e coloração amareloalaranjada (Tabela 1; Figuras 4K-N).

O Grupo Fitoclasto é menos abundante em relação aos demais grupos encontrados (Tabela 1; Figuras 4G-H). Esse grupo corresponde aos fragmentos de tecidos derivados de vegetais superiores. No geral, o fitoclasto do tipo não opaco é o de maior representatividade. Também foi registrada a ocorrência de fitoclasto em estado amorfizado (Tabela 1; Figuras 4E-F). Os outros componentes do grupo, como as membranas (tecido nãocelular de forma irregular e aparência degradada, com intensa fluorescência) e as cutículas (camada mais externa da epiderme foliar com coloração de amarelo pálido a marrom claro sob luz branca transmitida e amarelo intenso sob fluorescência), ocorrem em baixos percentuais (Tabela 1; Figuras 4I-J).

\section{COT (carbono orgânico total)}

O material analisado apresentou teores muito variados de COT desde 0,18 a 44,00\%, que reflete tanto a elevada quantidade de matéria orgânica depositada quanto o elevado grau de preservação. O enxofre total (ST) alcançou valores de até $3,05 \%$ (Tabela 2 ).

\section{Análise de agrupamento hierárquica}

De acordo com o tratamento estatístico Modo-R (Tabela 3; Figura 6), as amostras foram organizadas em quatro agrupamentos segundo o maior grau de similaridade dos componentes da matéria orgânica em relação ao "critério origem": o agrupamento A representa a matéria orgânica retrabalhada pela ação bacteriana (MOA e fitoclasto amorfizado); o agrupamento B corresponde aos componentes lacustres (algas de água doce); o agrupamento $\mathrm{C}$ corresponde aos componentes flúvio-lacustres (esporomorfo, membrana, cutícula e fitoclasto não opaco) e o agrupamento D representa os componentes lenhosos, principalmente os fitoclastos opacos.

O Modo-Q (Figura 7) subdividiu as amostras em seis associações de palinofácies, de acordo com a abundância dos grupos e subgrupos da matéria orgânica.

\section{Associações de palinofácies}

A Associação de Palinofácies I (Figura 7) corresponde ao predomínio do Grupo Matéria Orgânica Amorfa (MOA), ten-
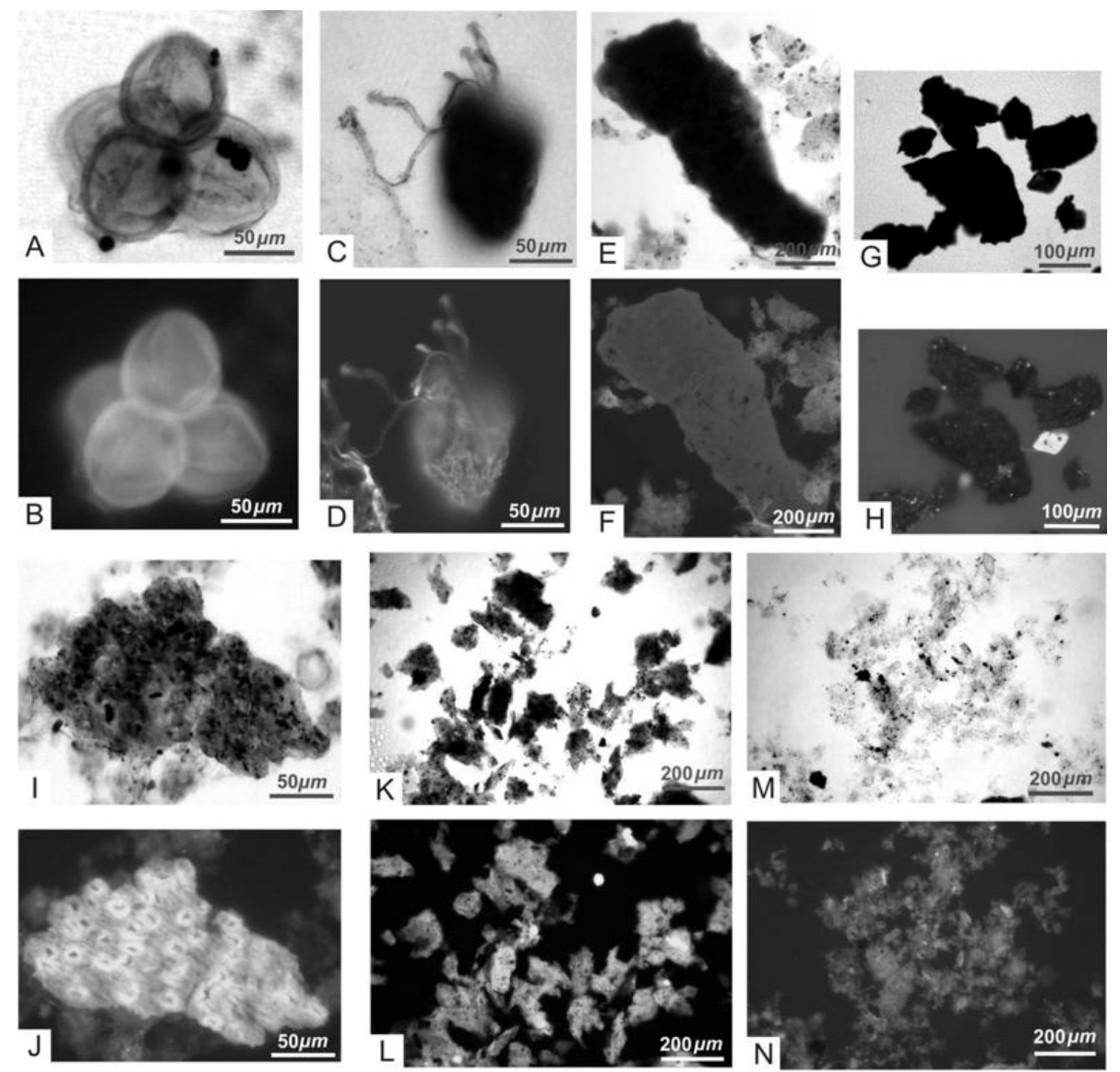

Figura 4. A-B, Rhoipites sp.; C-D, Azolla; E-F, fitoclasto amorfizado; G-H, fitoclasto opaco; I-J, cutícula; K-N, matéria orgânica amorfa. Fotomicrografias em A, C, E, G, I, K, M sob luz branca transmitida; em B, D, F, H, J, L, N sob luz azul/UV incidente (fluorescência).

Figure 4. A-B, Rhoipites sp.; C-D, Azolla; E-F, amorphous phytoclast; G-H, opaque phytoclast; I-J, cuticule; K-N, amorphous organic matter. Photomicrographs in A, C, E, G, I, K, M under transmitted white light; in B, D, F, H, J, L, N under incident blue light/ultralight light (fluorescence). 
Tabela 2. Valores percentuais do carbono orgânico total (COT) e enxofre total (ST). Abreviaturas: COT, carbono orgânico total; ST, enxofre total; RI, resíduo insolúvel.

Table 2. Values in percentage of total organic carbon (COT) and total sulfur (ST). Abbreviations: COT, total organic carbon; ST, total sulfur; RI, insoluble residue.

\begin{tabular}{c|c|c|c|c} 
Amo stra & Prof. (m) & COT \% & ST \% & RI\% \\
\hline P-37 & 23,50 & 0,18 & 1,07 & 84 \\
\hline P-73 & 40,80 & 1,03 & 0,05 & 84 \\
\hline P-1 15 & 59,20 & 7,8 & 0,35 & 72 \\
\hline P-1 40 & 78,50 & 4,16 & 0,10 & 79 \\
\hline P-1 64 & 97,30 & 7,41 & 1,06 & 80 \\
\hline P-1 87 & 115,65 & 5,34 & 0,24 & 80 \\
\hline P-2 08 & 134,80 & 5,14 & 3,05 & 74 \\
\hline P-2 27 & 154,00 & 3,30 & 0,81 & 75 \\
\hline P-243 & 171,28 & 2,05 & 0,21 & 81 \\
\hline P-254 A & 188,80 & 9,05 & 0,69 & 79 \\
\hline P-2 66 & 205,98 & 6,62 & 0,80 & 80 \\
\hline P-2 73 & 220,00 & 0,37 & 0,05 & 84 \\
\hline P-2 88 & 241,90 & 5,68 & 0,69 & 76 \\
\hline P-3 05 & 260,10 & 5,04 & 0,84 & 59 \\
\hline P-3 26 & 280,60 & 13,4 & 1,41 & 84 \\
\hline P-344 & 298,40 & 0,60 & - & 85 \\
\hline P-364 & 318,65 & 0,46 & 0,68 & 74 \\
\hline P-3 81 & 335,65 & 1,88 & 0,20 & 86 \\
\hline P-4 16 & 371,10 & 0,81 & 0,02 & 84 \\
\hline P-432 & 388,40 & 0,19 & - & 86 \\
\hline P-443 & 406,90 & 1,29 & - & 85 \\
\hline P-450 & 418,00 & 44,0 & 0,85 & 80 \\
\hline P-453 & 421,65 & 33,10 & 0,53 & 83 \\
\hline P-459 & 438,05 & 2,22 & 0,89 & 82 \\
\hline P-476 & 455,50 & 0,80 & 0,38 & 81 \\
\hline P-492 & 472,15 & 12,70 & 0,71 & 82 \\
\hline P-5 12 & 490,55 & 14,0 & 0,51 & 88 \\
\hline & & & & \\
\hline & & & & \\
\hline
\end{tabular}

Tabela 3. Descrição do tratamento estatístico Modo-R.

Table 3. Description of static treatment R-Mode.

\begin{tabular}{c|c} 
Agrupamento & Descrição \\
\hline A & MOA e fitoclasto amorfizado \\
\hline B & Algas de água doce \\
\hline C & $\begin{array}{r}\text { Es poromorfos, membrana, cutículas e } \\
\text { fitoclasto não opaco }\end{array}$ \\
\hline D & Componentes lenhosos \\
\end{tabular}

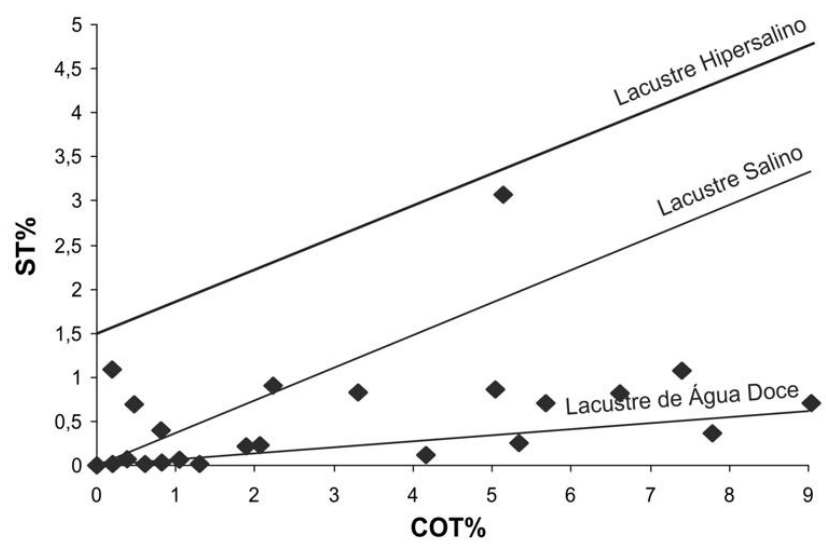

Figura 5. Diagrama binário mostrando os percentuais de carbono orgânico total (COT) e enxofre total (ST) das amostras analisadas (modificado de Leventhal, 1995).

Figure 5. Binary diagram showing the percentages of total organic carbon (COT) and sulfur total (ST) of the analyzed samples (modified from Leventhal, 1995).

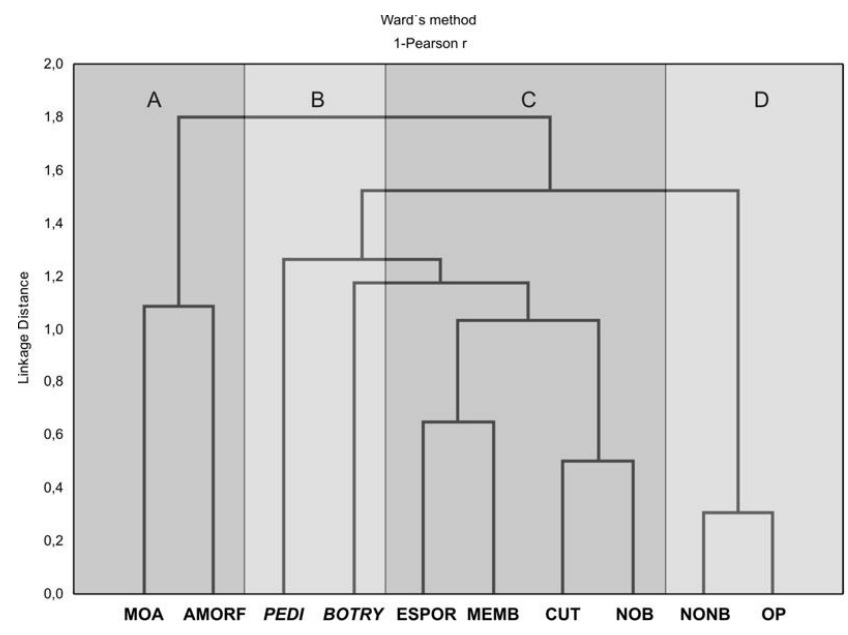

Figura 6. Dendograma produzido pela análise de agrupamento Modo R para os grupos e subgrupos de componentes da matéria orgânica do testemunho Pinda-1-SP. Agrupamentos: A, MOA e fitoclasto amorfizado; $\mathbf{B}$, algas de água doce; C, esporomorfo, membranas, cutículas e fitoclastos não opacos; D, componentes lenhosos. Abreviaturas: MOA, matéria orgânica amorfa; AMORF, fitoclasto amorfizado; PEDI, Pediastrum; BOTRY, Botryococcus; ESPOR, esporomorfo; MEMB, membrana; CUT, cutículas; NOB, fitoclasto não-opaco bioestruturado; NONB, fitoclasto não-opaco não-bioestruturado; OP, fitoclasto opaco.

Figure 6. Cluster made by analysis of assembly R-Mode for groups and subgroups of compounds of organic matter of the core Pinda-1-SP. Assemblies: A, AOM and Amorphous phytoclast; B, fresh water lacustrine algae; C, sporemorphs, membranes, cuticules, and phytoclast non-opaque; D, structured woody compounds. Abbreviations: MOA, amorphous organic matter; AMORF, amorphous phytoclasts; PEDI, Pediastrum; BOTRY, Botryococcus; ESPOR, sporemorphs; MEMB, membrane; CUT, cuticules; NOB, translucent structured phytoclast; NONB, translucent non-structured phytoclast; OP, opaque phytoclast. 
do em média $69,31 \%$ do total da matéria orgânica. O Grupo Fitoclasto e o Grupo Palinomorfo apresentaram moderado percentual (10-20\%). A elevada ocorrência do material amorfizado, relacionada a valores elevados de COT, pode indicar um ambiente restrito, estagnado. Esta associação é representada pelas amostras com profundidade de 335,65 m; $280,60 \mathrm{~m} ; 260,10 \mathrm{~m} ; 241,90 \mathrm{~m} ; 205,98 \mathrm{~m}$ e $188,80 \mathrm{~m}$, correspondendo aos intervalos 5 e 6 (Tabela 4, Figura 8).

Na Associação de Palinofácies II (Figura 7) predomina o Grupo Fitoclasto (52\% em média da associação), sendo representando essencialmente pelo subgrupo fitoclasto

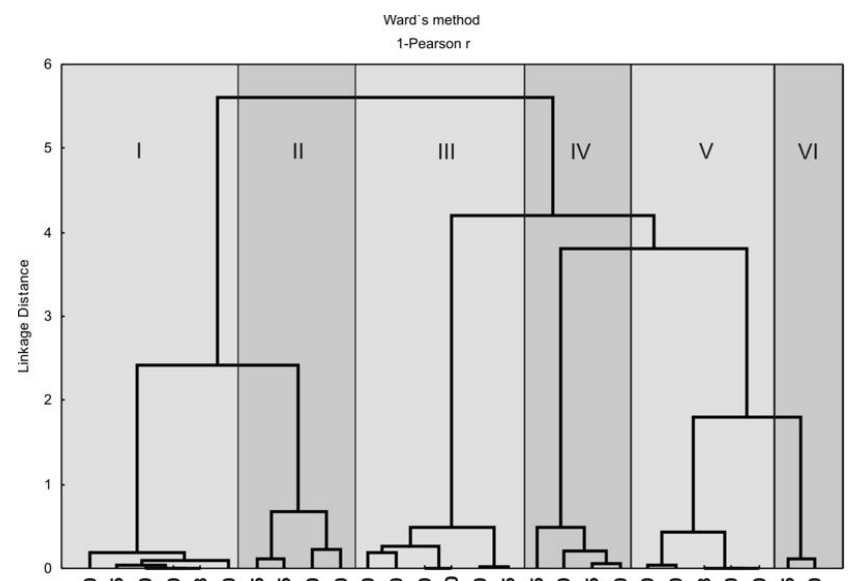

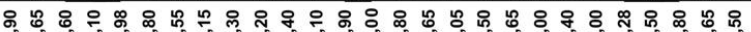

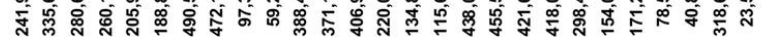

Figura 7. Dendograma produzido pela análise de agrupamento Modo $Q$ para os grupos e subgrupos de componentes da matéria orgânica do testemunho Pinda-1-SP em relação à profundidade. Associações de palinofácies: I, MOA; II, fitoclasto amorfizado; III, Botryococcus; IV, fitoclastos; V, Pediastrum; VI, palinomorfos terrestres.

Figure 7. Cluster made by analysis of assembly Q-Mode for the groups and subgroups of compounds of organic matter of the core Pinda-1-SP in relation to depth. Palynofacies associations: I, MOA; II, amorphous phytoclasts; III, Botryococcus; IV, phytoclasts; V, Pediastrum; VI, terrestrial palynomorphs. amorfizado. Este subgrupo é composto por partículas que exibem aspecto de matéria amorfa com contorno difuso, irregular, fluorescência relativamente alta e coloração entre amarela e laranja (Mendonça Filho et al., 2009). A alta intensidade de fluorescência destes componentes pode estar relacionada a um ambiente alcalino, variando de salino a hipersalino que, por sua vez, indica uma elevada atividade bacteriana. $\mathrm{O}$ Grupo MOA compõe $23,25 \%$ da associação e as algas do gênero Botryococcus, $16 \%$. Os demais grupos e subgrupos da matéria orgânica ocorrem em baixo percentual (5\%). Nesta associação, estão inseridas as amostras com profundidade de 490,55 m; 472,15 m; 97,30 m e 59,20 m correspondendo aos intervalos 1 e 8 (Tabela 4, Figura 8).

A Associação de Palinofácies III (Figura 7) mostra a predominância do Grupo Palinomorfo, principalmente algas do gênero Botryococcus $(58,93 \%)$. O subgrupo dos esporomorfos está representado, essencialmente por grãos de pólen. Segundo Tyson (1995), espécies do gênero Botryococcus são oligotróficas e eurihalinas. À medida que ocorre redução na lâmina d'água, em função do aumento da taxa de evaporação, ocorre também um aumento na salinidade, o que pode levar a um aumento da concentração de Botryococcus e também de sua relativa flutuação. Esta associação está representada pelas amostras com profundidade $406,90 \mathrm{~m} ; 388,40 \mathrm{~m} ; 371,10 \mathrm{~m} ; 220,00 \mathrm{~m} ; 134,80 \mathrm{me} 115,65 \mathrm{~m}$, que correspondem aos intervalos 4, 6 e 7 (Tabela 4, Figura 8).

A Associação de Palinofácies IV (Figura 7) apresenta o predomínio do Grupo Fitoclasto, principalmente os subgrupos fitoclasto não opaco e opaco $(73,37 \%)$. Os fitoclastos amorfizados ocorrem em baixo percentual (2,53\%), juntamente com o Grupo MOA $(0,25 \%)$ e Grupo Palinomorfo $(20 \%)$. Esta associação está representada pelas amostras com profundidade 455,50 m; 438,05 m; 421,65 m e 418,00 m, relacionadas aos intervalos 2 e 3 (Tabela 4, Figura 8).

A Associação de Palinofácies V (Figura 7) corresponde essencialmente ao Grupo Palinomorfo com o predomínio de algas do gênero Pediastrum (70,24\%). Os demais grupos e

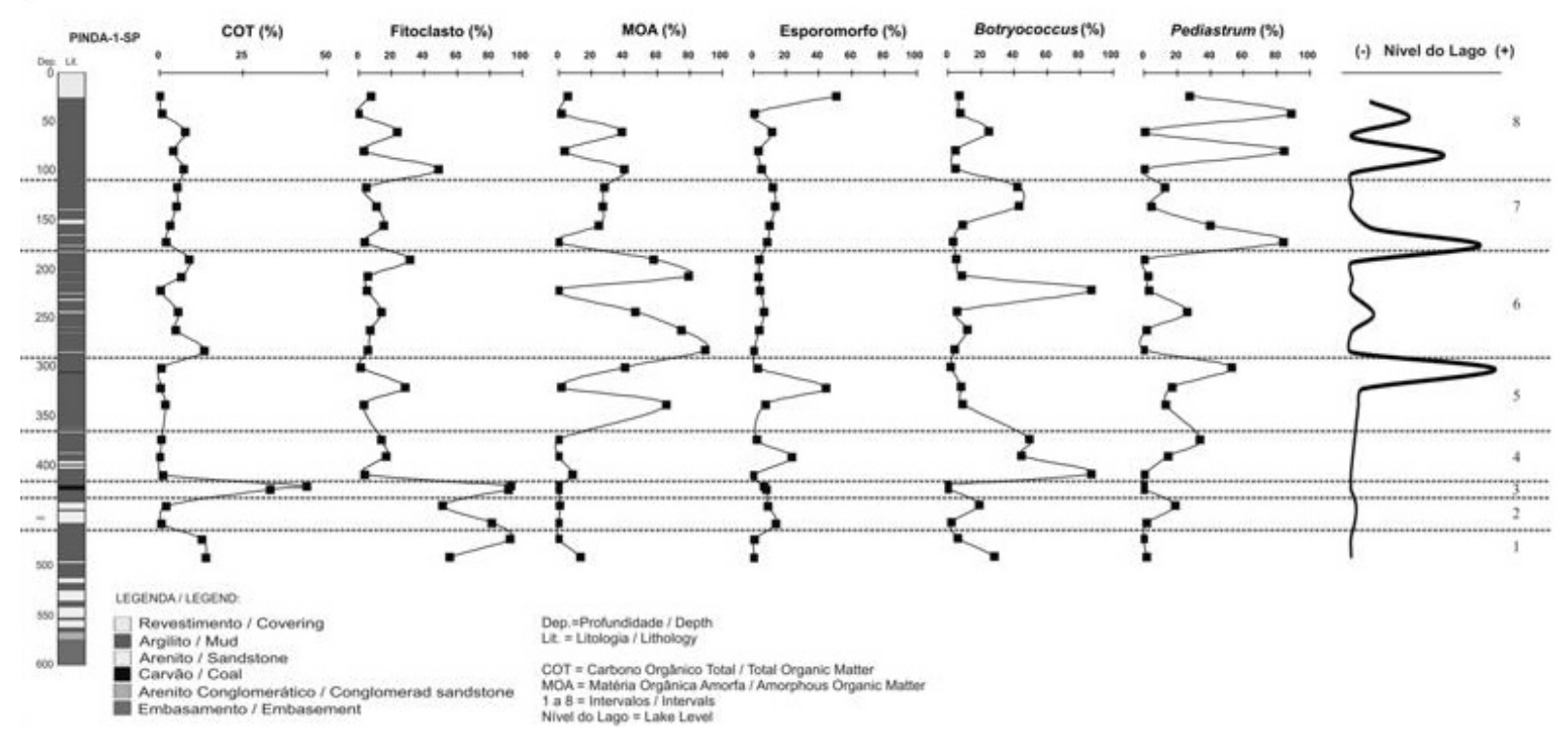

Figura 8. Variação dos parâmetros palinofaciológicos e organogeoquímicos dos principais grupos e subgrupos do querogênio mostrando a variação do nível do lago.

Figure 8. Organic facies and organic geochemistry parameters variation of the main groups showing the lake base level oscillations. 
Tabela 4. Relação dos percentuais entre dados organofaciológicos e organogeoquímicos de cada amostra da Formação Tremembé Abreviaturas: Fito total, fitoclasto total; MOA, matéria orgânica amorfa total; Palino Total, palinomorfo total; COT, carbono orgânico total; Ass. Palino, associação de palinofácies.

Table 4. Relation in percentage between organic facies and organic geochemistry data of each sample of Tremembé Formation. Abbreviations: Fito Total, total phytoclasts; MOA, total amorphous organic matter; Palino Total, total palynomorphs; COT, total organic carbon; Ass. Palino, palynofacies association.

\begin{tabular}{|c|c|c|c|c|c|c|c|}
\hline Amostra & Prof. (m) & Fito Total & MOA & Palino Total & COT & Ass. Palino. & Interva lo \\
\hline P37 & 23,50 & 7,9 & 6,0 & 86,1 & 0,18 & VI & \multirow{5}{*}{8} \\
\hline P73 & 40,80 & 0,0 & 2,0 & 98,0 & 1,03 & $\mathrm{~V}$ & \\
\hline P115 & 59,20 & 23,5 & 38,7 & 37,8 & 7,79 & II & \\
\hline $\mathrm{P} 140$ & 78,50 & 3,3 & 3,9 & 92,8 & 4,16 & $\mathrm{~V}$ & \\
\hline P164 & 97,30 & 49,2 & 40,5 & 10,3 & 7,41 & II & \\
\hline média & & 16,8 & 18,2 & 65,0 & 4,11 & & \\
\hline P187 & 115,65 & 4,7 & 28,1 & 67,3 & 5,34 & III & \multirow{4}{*}{7} \\
\hline P208 & 134,80 & 11,1 & 27,3 & 61,6 & 5,14 & III & \\
\hline P227 & 154,00 & 15,5 & 24,7 & 59,8 & 3,30 & $\mathrm{~V}$ & \\
\hline P243 & 171,28 & 3,7 & 0,0 & 96,3 & 2,05 & $\mathrm{~V}$ & \\
\hline média & & 16,8 & 23,1 & 60,1 & 4,6 & & \\
\hline P254 A & 188,80 & 31,8 & 58,1 & 10,1 & 9,05 & I & \multirow{6}{*}{6} \\
\hline P266 & 205,98 & 5,7 & 79,4 & 14,9 & 6,62 & I & \\
\hline P273 & 220,00 & 5,6 & 0,0 & 94,4 & 0,37 & III & \\
\hline P288 & 241,90 & 14,0 & 47,2 & 38,8 & 5,68 & I & \\
\hline P305 & 260,10 & 7,1 & 75,1 & 17,8 & 5,04 & I & \\
\hline P326 & 280,60 & 5,7 & 89,9 & 4,5 & 13,40 & I & \\
\hline média & & 11,6 & 58,3 & 30,1 & 6,69 & & \\
\hline P344 & 298,40 & 1,3 & 40,8 & 58,0 & 0,60 & $\mathrm{~V}$ & \multirow{3}{*}{5} \\
\hline P364 & 318,65 & 28,6 & 1,8 & 69,6 & 0,46 & $\mathrm{VI}$ & \\
\hline P381 & 335,65 & 3,3 & 66,2 & 30,5 & 1,88 & I & \\
\hline média & & 11,1 & 36,2 & $\mathbf{5 2 , 7}$ & 1,0 & & \\
\hline P416 & 371,10 & 13,9 & 0,0 & 86,1 & 0,81 & III & \multirow{3}{*}{4} \\
\hline P432 & 388,40 & 16,8 & 0,0 & 83,2 & 0,19 & III & \\
\hline P443 & 406,90 & 4,0 & 8,5 & 87,5 & 1,29 & III & \\
\hline média & & 11,5 & 2,8 & 85,6 & 0,8 & & \\
\hline $\mathrm{P} 450$ & 418,00 & 93,1 & 0,0 & 6,9 & 44,00 & IV & \multirow{2}{*}{3} \\
\hline $\mathrm{P} 453$ & 421,65 & 92,0 & 0,0 & 8,0 & 33,10 & IV & \\
\hline média & & 92,5 & $\mathbf{0 , 0}$ & 7,5 & 38,5 & & \\
\hline P459 & 438,05 & 51,6 & 1,0 & 47,4 & 2,22 & IV & \multirow{2}{*}{2} \\
\hline P476 & 455,50 & 81,7 & 0,0 & 18,3 & 0,80 & IV & \\
\hline média & & 66,6 & 0,5 & 32,8 & 1,5 & & \\
\hline P492 & 472,15 & 92,5 & 0,0 & 7,5 & 12,70 & II & \multirow{2}{*}{1} \\
\hline P512 & 490,55 & 56,0 & 13,8 & 30,2 & 14,00 & II & \\
\hline média & & 74,3 & 6,9 & 18,9 & 13,3 & & \\
\hline
\end{tabular}


subgrupos da matéria orgânica ocorrem com moderados percentuais (5-15\%). Espécies do gênero Pediastrum são eutróficas e estenohalinas e parecem ser mais abundantes em lagos tropicais e subtropicais permanentes e de baixa salinidade (Esteves, 1988; Tyson, 1995). As mudanças do estado do lago de oligotrófico para eutrófico resultam, usualmente, na diminuição da razão Botryococcus/Pediastrum. Essa associação é representada pelas amostras com profundidade de 298,40 m; 171,28 m; 154,00 m; 78,50 m e 40,80 m, sendo associadas aos intervalos 5, 7 e 8 (Tabela 4, Figura 8).

Na Associação de Palinofácies VI (Figura 7) há o predomínio do Grupo Palinomorfo, essencialmente dos esporomorfos $(47,8 \%)$, sendo representados pelas amostras com profundidade $318,65 \mathrm{me} 23,50 \mathrm{~m}$, que foram associadas aos intervalos 5 e 8 (Tabela 4, Figura 8). Esta associação também apresenta um moderado percentual de ocorrência de algas do gênero Pediastrum $(22,4 \%)$ e do Grupo Fitoclasto $(18,25 \%)$.

\section{DISCUSSÃO}

Para a interpretação, o testemunho analisado foi subdividido em oito intervalos, a partir das associações geradas de acordo com o agrupamento Modo-Q, tendo em vista a variação dos grupos e subgrupos da matéria orgânica, resultando assim, em uma possível interpretação para a variação do nível do lago, da base para o topo (Figura 8).

O Intervalo 1 (490,55-472,15 m) é composto pela Associação de Palinofácies II (Figura 7; Tabela 4). A alta abundância dos fitoclastos amorfizados juntamente com baixa percentagem de algas de água doce, indicam um ambiente mais calmo, após um período de alto fluxo fluvial com a deposição dos fitoclastos. Este material amorfizado associado a elevados valores de COT também evidencia um ambiente estagnado. A ocorrência de algas do gênero Botryococcus indica que, em determinado momento, esse ambiente deposicional apresentou alta luminosidade e alta salinidade, pois essas algas são eurihalinas e traduzem uma condição de nível baixo da lâmina d'água.

O Intervalo 2 (455,50-438,05 m) corresponde à Associação de Palinofácies IV (Figura 7; Tabela 4). Em relação ao intervalo anterior, verifica-se um aumento na participação do Grupo Fitoclasto, que estaria associado ao transporte fluvial ou pelo vento que, associado ao aporte sedimentar, favorece uma possível agitação da água e o estabelecimento de condições mais oxidantes, com diminuição da luminosidade e, consequentemente, uma baixa ocorrência de algas do gênero Botryococcus. O aumento no percentual do Grupo Palinomorfo, especialmente do subgrupo Pediastrum, também pode estar relacionado à diminuição da salinidade. $\mathrm{O}$ pulso no aumento do aporte fluvial e pluvial, seguido por um período de calmaria, tranquilidade e estratificação luminosa na coluna de água, sugerem aumento na quantidade de nutrientes, que favoreceu à reprodução de Pediastrum. A elevação no percentual dos esporomorfos, principalmente os esporos, pode reforçar a idéia de que o clima se tornou mais úmido em relação ao intervalo anterior, ressaltando, assim, a contribuição terrestre. As cutículas bem preservadas, principalmente com estômatos preservados, também indicam clima mais úmido e proximidade da área fonte. As amostras deste intervalo apresentam valores de COT em média 1,5\%, sugestivo de que nesses ambientes oxidantes os fitoclastos predominam.
Na passagem do intervalo 1 para o intervalo 2 ocorre um ligeiro aumento da espessura da lâmina de água e o estabelecimento de um ambiente mais distal, indicado pela diminuição no percentual dos fitoclastos em direção ao topo do intervalo e aumento do Pediastrum em relação ao intervalo anterior. Pediastrum é uma alga de água doce com propriedades estenohalinas e sua presença reflete maior quantidade de nutrientes.

O Intervalo 3 (421,65-418,00 m) também corresponde à Associação de Palinofácies IV (Figura 7; Tabela 4). Neste intervalo encontrou-se um considerável percentual do subgrupo dos esporomorfos, representado pelos esporos ornamentados. O material deste intervalo encontra-se carbonizado e pode indicar deposição em um ambiente estagnado, com condições redutoras, sem indícios de aporte fluvial e, consequentemente, sujeito a processo de lenta decomposição orgânica. Portanto, este intervalo pode estar relacionado a um ambiente pantanoso (turfeira), uma vez que apresenta alta concentração de matéria orgânica e elevados valores de COT $(33,10$ e 44,0\%). A diversidade de material palinológico pode ser considerada indicativa da variabilidade proximaldistal da área fonte, ou seja, a presença de esporos ornamentados indica deposição em clima úmido e também expressam a característica de ambiente deposicional mais proximal em relação a esporos sem ornamentação e grãos de pólen. $\mathrm{Na}$ passagem do Intervalo 2 para o Intervalo 3 pode-se dizer que a contribuição fluvial foi mínima, não há variação significativa na espessura da lâmina de água.

O Intervalo 4 (406,90-371,10 m) está representado pela Associação de Palinofácies III (Figura 7; Tabela 4). Neste intervalo ocorre o predomínio de algas do gênero Botryococcus. A MOA e os fitoclastos apresentam baixo percentual (2,83 e 11,56\%, respectivamente). A predominância de Botryococcus pode ser indício de um ambiente de águas mais calmas, sem perturbação, sem vento, com alta taxa de evaporação e consequente diminuição da lâmina de água, alta luminosidade e elevação da salinidade, permitindo desenvolvimento de organismos eurihalinos. Esses esporomorfos, principalmente os esporos, indicam área fonte mais proximal em relação à deposição de grãos de pólen e algas de água doce. Além disso, a presença de Azolla também pode ser um indicativo de ambiente de deposição mais úmido e de proximidade da área fonte. Na passagem do Intervalo 3 para o Intervalo 4 , a grande concentração de Botryococcus evidencia diminuição na espessura da lâmina d'água.

O Intervalo 5 (335,65-298,40 m) é constituído pelas Associações de Palinofácies I, VI e V (Figura 7; Tabela 4). A presença de MOA na base deste intervalo indica ambiente de baixa energia e coluna de água anóxica. A considerável elevação na quantidade do subgrupo esporomorfo indica que seu transporte pode ter ocorrido pelo aumento no aporte sedimentar, pelo vento ou pela chuva. Com isso, a coluna de água inicia o processo de oxigenação, aumentando a quantidade de nutrientes, que provoca a floração de Pediastrum, e a consequente diminuição de Botryococcus, que indica um aumento da lâmina de água. Portanto, pode-se dizer que ocorreu uma mudança no estado trófico do lago, que passou de oligotrófico para eutrófico. Na passagem do Intervalo 4 para o Intervalo 5 ocorreu um aumento da espessura da lâmina de água em função da biomassa "autóctone". 
O Intervalo 6 (280,60-188,80 m) está representado pelas Associações de Palinofácies I e III (Figura 7; Tabela 4). A grande abundância da MOA indica ambientes com condições redutoras no ambiente, coluna de água anóxica e alta produtividade primária. Como no intervalo anterior, a elevada abundância de MOA é característica de áreas com alta preservação de matéria orgânica com intenso retrabalhamento microbiológico em função das condições redutoras, especialmente em áreas de alta produtividade primária (valores de COT variando de 5,04 a $13,40 \%)$. Ocorreu uma diminuição na quantidade de esporomorfos, que indica diminuição da sua deposição, tanto pelo rio como pelo vento, que favorece a idéia de um ambiente mais seco. Em relação à análise dos intervalos anteriores, o intervalo 6 apresenta uma intercalação entre MOA e Botryococcus, sugestivo de diminuição na espessura da lâmina de água e de estabelecimento de condições hipersalinas novamente. Na passagem do Intervalo 5 para o Intervalo 6, verifica-se um aumento na espessura da lâmima d'água.

O Intervalo $7(171,28-115,65 \mathrm{~m})$ compreende as Associações de Palinofácies V e III (Figura 7; Tabela 4). Na base deste intervalo foi encontrada alta concentração de algas do gênero Pediastrum, o que sugere que ocorreu um aumento na produtividade primária e um aumento na espessura da lâmina de água, acarretando assim a diminuição da luminosidade, sob vigência de clima mais úmido. A MOA menos densa que foi encontrada era de origem das algas do gênero Pediastrum que se encontravam em estado amorfizado. Assim, a decomposição da matéria orgânica resultou na diminuição da quantidade do oxigênio presente, tendendo para um ambiente deposicional com condições anóxicas. Para corroborar os indícios de ambiente mais úmido, observou-se o aumento na quantidade de esporomorfos. Em direção ao topo, há diminuição de Pediastrum e aumento de Botryococcus, sugerindo aumento da taxa de evaporação do lago, o que levou à diminuição da lâmina de água e o aumento da luminosidade e da salinidade, indicando que o ambiente tornouse mais seco. Na passagem do Intervalo 6 para o Intervalo 7 ocorre redução na espessura da lâmina d'água.

O Intervalo $8(97,30-23,50 \mathrm{~m})$ está representado pelas Associações de Palinofácies V, II e IV (Figura 7; Tabela 4). Nesse intervalo registrou-se baixo percentual de esporomorfos $(14,52 \%)$ e a intercalação de fitoclasto amorfizado com algas do gênero Pediastrum. Como discutido para os intervalos anteriores, os fitoclastos amorfizados indicam ambiente deposicional com baixa energia. A alga do gênero Pediastrum sugere a ocorrência de aporte sedimentar seguido de período de calmaria. A presença dos esporomorfos, principalmente grãos de pólen, carregados pelo vento ou pelos rios, indicam que o ambiente está mais distal. Na passagem do Intervalo 7 para o Intervalo 8 ocorreram oscilações na espessura da lâmina de água em determinados momentos.

\section{CONCLUSÕES}

A alternância entre o domínio de Pediastrum e de Botryococcus permitiu inferir flutuações no nível de base do lago. Algas do gênero Botryococcus são abundantes quando a lâmina de água está baixa, sugerindo condições ambientais de menor energia, águas mais salinas, clima mais seco, maiores taxas de evaporação e maior luminosidade. Entretanto, eventos que culminaram na re-expansão do lago fizeram das algas do gênero Pediastrum a forma mais abundante, devido à diminuição da salinidade, à maior energia do ambiente, ao clima mais úmido, e ao aumento de nutrientes e da produtividade primária. Tais condições também foram evidenciadas pela ocorrência dos grupos Matéria Orgânica Amorfa e Palinomorfo, essencialmente os esporomorfos. A elevada abundância do material amorfizado, associada a altos valores de carbono orgânico permitiu inferir o estabelecimento de ambientes estagnados e, sob elevada fluorescência, indicaram ambientes mais salinos. A ocorrência do subgrupo esporomorfo indicou clima mais úmido e determinou a relação proximal-distal da área fonte.

A partir das análises organofaciológica e organogeoquímica, pode-se concluir que a deposição da sucessão sedimentar da Formação Tremembé aqui analisada representa antigos depósitos lacustres de água doce, com regime oxidante, variando até ambiente salino restrito, com regime disóxico-anóxico.

\section{AGRADECIMENTOS}

Os autores agradecem ao CNPq pelo apoio financeiro e bolsa PIBIC (projetos 306925/2006-0 e 490416/2007-1) e ao projeto CT-Petro/Finep 21.01.0347-00, pela cessão de amostras.

\section{REFERÊNCIAS}

Combaz, A. 1964. Les palynofacies. Revue de Micropaléontologie, 7:205-218.

Esteves, F.A. 1988. Fundamentos de Limnologia. Editora Interciência, Rio de Janeiro, 575 p.

Fernandes, F.L. 1993. Arcabouço estrutural e evolução da bacia de Taubaté - SP. Programa de Pós-graduação em Evolução Crustal e Recursos Naturais, Universidade Federal de Ouro Preto, Dissertação de Mestrado, 147 p.

Leventhal, J.S. 1995. Carbon-sulfur plots to show diagenetic and epigenetic sulfidation in sediments. Geochimica et Cosmochimica Acta, 59(6):1207-1211.

Mendonça Filho, J.G. 1999. Aplicação de estudos de palinofácies e fácies orgânica em rochas do Paleozóico da Bacia do Paraná, sul do Brasil. Programa de Pós-graduação em Geociências, Universidade Federal do Rio Grande do Sul,Tese de Doutorado, 338 p.

Mendonça Filho, J.G.; Carvalho, M.A. \& Menezes, T.R. 2002. Palinofácies. In: T.L. Dutra (org.) Técnicas e procedimentos de trabalho com fósseis e formas modernas comparativas, Editora Unisinos, p. 20-24.

Mendonça Filho, J.G.; Menezes, T.R.; Mendonça, J.O.; Oliveira, A.D.; Carvalho, M.A.; Santanna, A.J. \& Souza, J.T. 2009. Palinofácies. In: I.S. Carvalho (org.) Paleontologia, Editora Interciência, no prelo.

Molinari, L. 2003. Interpretação sismoestratigráfica da Bacia de Taubaté - SP. Instituto de Geociências, Universidade Federal do Rio de Janeiro, Monografia de Conclusão de Curso, 68 p.

Riccomini, C. 1989. O rift continental do sudeste do Brasil. Instituto de Geociências, Universidade de São Paulo, Tese de Doutorado, 256 p.

Torres-Ribeiro, M. 2004. Fácies microclásticas de um sistema lacustre oligocênico do sudeste do Brasil (Formação Tremembé, Bacia de Taubaté). Programa de Pós-graduação em Geociências, Universidade Federal do Rio de Janeiro, Dissertação de Mestrado, $122 \mathrm{p}$.

Tyson, R.V. 1995. Sedimentary organic matter. Organic facies and palynofacies. Londres, Chapman \& Hall, 615 p.

Valentin, J.L. 2000. Ecologia numérica. $1^{\text {a }}$ ed. Rio de Janeiro, Editora Interciência, $117 \mathrm{p}$.

Received in June, 2009; accepted in October, 2009. 